\title{
Thyrotoxicosis in an Elderly Patient Simulating Infectious Gastroenteritis
}

\author{
Moe $\mathrm{TO}^{1 *}$, Htwe $\mathrm{TH}^{2}$, Yin $\mathrm{TA}^{3}$ and Ani ${ }^{2}$
}

${ }^{1}$ Department of Geriatric Medicine and General Internal Medicine, Sandwell and West Birmingham Hospitals NHS, Birmingham, UK

${ }^{2}$ Department of General Internal Medicine, Heart of England NHS, Birmingham, UK

${ }^{3}$ Department of Respiratory Medicine, Doncaster Royal Infirmary, Doncaster and Bassetlaw Hospitals NHS, UK

\begin{abstract}
A case of "apathetic" hyperthyroidism in which an elderly lady presented with symptoms of gastroenteritis was described. Thorough clinical assessment and systematic diagnostic work up are imperative to confirm an occult thyroid disorder as undiagnosed thyroid illness could cause a variety of adverse outcomes in old age.
\end{abstract}

Keywords: Apathetic hyperthyroidism; Presentation; Diagnosis; Management

\section{Introduction}

Thyroid disorders are common medical problems in older people, especially women. The thyroid disorders include overt and subclinical hypo/hyperthyroidism, sick euthyroid syndrome, goitres, thyroid carcinoma, apathetic hyperthyroidism [1]. In older people clinical features of thyroid disorders could sometimes not be clear and straightforward. Age-related physiological changes in the endocrine system, existing co-morbidities and polypharmacy might cause complexity in diagnosing underlying thyroid illnesses.

\section{Case History}

88 years old woman presented acutely with 10 days history of diarrhoea, nausea, and vomiting. She suffered about 6-7 episodes of loose stool everyday. Her diarrhoea was a watery, loose stool without having any blood or mucus. She had vomited 2-3 times everyday, associating with nauseous feeling. Neither coffee coloured granules nor blood was noticed in her vomit. In addition to above symptoms, her complaint of intermittent, colicky type pain below umbilicus. Her subjective pain score was 6 out of 10 . She was also very lethargic and had loss of appetite. Her background medical history included type II diabetes mellitus, TIA (transient ischaemic attack), gastro-oesophageal reflux, osteoarthritis and hypertension. Her medications included Gliclazide $80 \mathrm{mg}$ OD, Metformin 1g BD, Bendroflumethiazide $2.5 \mathrm{mg}$ OD, Amlodipine $10 \mathrm{mg}$ OD, Paracetamol 1g QDS, Lansoprazole $30 \mathrm{mg}$ OD and Aspirin $75 \mathrm{mg}$ OD.

On admission she seemed to be generally tired and weak. Her vital parameters were noted as blood pressure $100 / 60 \mathrm{mmHg}$, pulse rate $96 / \mathrm{min}$ in regular rhythm, respiratory rate $16 / \mathrm{min}$, oxygen saturation $98 \%$ on room air and body temperature $36.4^{\circ} \mathrm{C}$. Clinical examination revealed dry tongue, reduced skin turgor and mild tenderness in the right iliac fossa. No evidence of regional lymph node enlargement, and any other palpable lump were noted. Per rectal examination showed only presence of watery stool. Her 12-leads ECG showed sinus tachycardia. The Chest and abdominal X-rays did not show any acute radiological findings. Her blood results showed haemoglobin 11.9 (normal range 12.1-15.1 g/dL), white cell count 11.8 (normal range 3.5-11.0 $10^{\%} / \mathrm{L}$ ), MCV 90.1 (normal range 82.0-102.0 fl), platelets 164 (normal range $150-50010 / \mathrm{L}$ ), sodium $118 \mathrm{mmol} / \mathrm{l}$ (normal range 133-146), potassium $4.7 \mathrm{mmol} / \mathrm{l}$ (normal range $3.5-5.5$ ), urea $11.1 \mathrm{mmol} / \mathrm{l}$ (normal range 2.5-7.8), creatinine $121 \mathrm{umol} / \mathrm{l}$ (normal range $60-110) \mathrm{Mg} 0.48 \mathrm{mmol} / \mathrm{l}$ (normal range $0.7-1.0$ ), phosphate $0.44 \mathrm{mmol} / \mathrm{l}$ (normal range 0.80 1.50), CRP $64 \mathrm{mg} / \mathrm{L}$ (normal range 0-5). The 8-hourly blood glucose monitoring showed her random blood glucose, ranging between 3.5 and $5.5 \mathrm{mmol} / \mathrm{l}$.

\section{Differential diagnoses were considered as}

- Infectious gastroenteritis or colitis

- Occult intra-abdominal malignancy

- $\quad$ Celiac disease and

- $\quad$ Appendicitis.

The initial management included fluid replacement with electrolytes correction, withholding of all anti-hypertensives, Lansoprazole, Gliclazide and a reduction of the dose of Metformin (500 mg BD).

In order to exclude an occult intra-abdominal malignancy the Computed Tomography (CT) chest, abdomen and pelvis with contrast was conducted. Stool culture for bacterial and viral pathogen detection, Thyroid Function Tests (TFT), serum B12, folate, ferritin, celiac screen, tumour markers (CA 125, CA19-9) were also requested. CT scan showed no radiological evidence of any intra-abdominal malignancy. TFT showed TSH $0.02 \mathrm{mU} / \mathrm{l}$ (normal range 0.35-4.94), free T4 $28.4 \mathrm{ng}$ / $\mathrm{dL}(0.8-1.8 \mathrm{ng} / \mathrm{dL})$ and T3 $2.2 \mathrm{nmol} / \mathrm{L}(1.2-3.1)$. All other investigations were unremarkable. Subsequent thyroglobulin autoantibody test was positive. She did not have any classical clinical sign of hyperthyroidism such as exophthalmos, goitre, bruit, tremor, hyperkinesia.

Having diagnosed autoimmune thyrotoxicosis (Graves' disease), she was treated with oral Carbimazole $20 \mathrm{mg}$ OD, intravenous Hydrocortisone $200 \mathrm{mg}$ stat followed by $100 \mathrm{mg}$ TDS for 3 days. All her symptoms were settled with overall clinical improvements within three days. Her electrolyte imbalances were also completely corrected. In the follow-up clinic four weeks later she returned to her normal activities with resulting in significant improvements of TFT. Her Carbimazole dose was gradually tailed off from 20 to $10 \mathrm{mg}$ and then to $5 \mathrm{mg}$ with serial monitoring of TFT and clinical assessment.

\section{Discussion}

The most common cause of acute diarrhoea and abdominal pain in the elderly is infectious gastroenteritis [2]. Cases of acute diarrhoea

*Corresponding author: Moe T Oo, Department of Geriatric Medicine and General Internal Medicine, Sandwell and West Birmingham Hospitals NHS, Birmingham, UK Tel: 0044-1215531831; E-mail: moethaw.oo@nhs.net

Received September 19, 2014; Accepted November 21, 2014; Published November 24, 2014

Citation: Moe TO, Htwe TH, Yin TA, Ani T (2014) Thyrotoxicosis in an Elderly Patient Simulating Infectious Gastroenteritis. J Clin Case Rep 4: 454. doi:10.4172/21657920.1000454

Copyright: $\odot 2014$ Moe TO, et al. This is an open-access article distributed under the terms of the Creative Commons Attribution License, which permits unrestricted use, distribution, and reproduction in any medium, provided the original author and source are credited. 
Citation: Moe TO, Htwe TH, Yin TA, Ani T (2014) Thyrotoxicosis in an Elderly Patient Simulating Infectious Gastroenteritis. J Clin Case Rep 4: 454. doi:10.4172/2165-7920.1000454

should be considered infective until proven otherwise. The aging process influences homeostatic mechanisms, making the elderly more susceptible to enteric pathogens [3]. A clear history and appropriate investigations should identify the causative organism. Negative stool cultures and PCR for viral pathogens should lead to consideration of other diagnoses.

As in our patient's presentations hyperthyroidism in old age can present with non-specific vague symptoms such as nausea, vomiting, lethargy, fatigue [4,5]. This form of hyperthyroidism is known as "Apathetic" or non-activated hyperthyroidism [4,5]. It is principally found in the elderly population and the usual hyperkinetic presentation of thyrotoxicosis is replaced by apathy and inactivity, making it difficult to diagnose [6]. Untreated hyperthyroid state increases risks of angina, heart failure and atrial fibrillation in the elderly [4]. Osteoporosis could occur as a result of increased bone turnover [4].

There are different causes of hyperthyroidism. Among these causes Graves' disease (autoimmune) is the most common cause of hyperthyroidism. Raised free T4 or T3, low TSH and presence of thyroglobulin antibodies could confirm the diagnosis of Garves' disease $[4,7,8]$.

Management of hyperthyroidism comprises three main stays of management; drugs therapy, surgery and radioactive iodine treatment [5]. Surgery is not a popular choice in older patients as these patients usually have multiple co-morbidities and present as high risk for operation [5]. Either drug therapy or radioactive iodine treatment is favourable [5]. If drug therapy is chosen, Propylthiouracil 200-400 $\mathrm{mg}$ or Carbimazole $20-40 \mathrm{mg}$ (once daily or divided dose) is used as initial treatment [4]. This initital treatment should be continued until an euthyroid state is established, which can take 4-8 weeks to reach [4]. Therefore, TFTs should be repeated in 2-4 weeks time after introducing the initial treatment [4]. After achieving an euthyroid state, two main treatment options should be considered; titration regimen (antithyroid dose is gradually reduced to a maintenance dose of Carbimazole $5-15 \mathrm{mg}$ or Propylthiouracil 50-150 mg daily with continued monitoring of TFTs) or block and replacement regimen (High dose antithyroid is continued to switch off thyroid synthetic function completely and levothyroxine is commenced promptly when free T4 level is supressed) [4]. Drug sideeffects of carbimazole include agranulocytosis and propylthiouracil can cause hepatotoxicity [4,7]. Beta-blockers are indicated only for controlling symptoms such as symptomatic tachycardia [5]. A short course of systemic steroids could be administered if patients are in an acute phase of hyperthyroidism or a thyroid crisis [8].

In our patient Carbimazole $20 \mathrm{mg}$ was initially introduced following a titration regimen as above. She had well tolerated to the treatment and did not present any side effect of the drug.

\section{Conclusion}

This case clearly reminds us that hyperthyroidism should be considered as an important differential diagnosis if an elderly patient presents with vague non-specific symptoms. Acute diarrhoea is uncommon in apathetic hyperthyroidism whilst infectious gastroenteritis remains the most common cause and should be excluded before alternative diagnoses are sought.

\section{References}

1. Carroll CT (2010) Thyroid disease in older age. CME Geiriatric Medicine 12 59-66.

2. Dundas S, Todd WTA (2006) Acute diarrhoea and fever. JR Coll Physicians Edinburgh 36: 236-240

3. Ratnaike RN (1999) Diarrhoea and aging. J Postgrad Med 45: 60-66.

4. Bowker L, Price J, Smith S (2006) Oxford Handbook of Geriatric Medicine. Oxford University Press 472-473.

5. Rehman SU, Cope DW, Senseney AD, Brzezinski W (2005) Thyroid disorders in elderly patients. South Med J 98: 543-549.

6. Palacios A, Cohen MA, Cobbs R (1991) Apathetic hyperthyroidism in middle age. Int J Psychiatry Med 21: 393-400.

7. FDA Med Watch Safety Alerts for Human Medical Products. Propylthiouracil (PTU). US Food and Drug Administration.

8. Kumar P, Clark M (2006) Chapter of Endocrine disease: Hyperthyroidism Clinical Medicine. (6thedn) 